\title{
Constraint-Induced Linguistic Therapy for Aphasic Patients in Hungary
}

\author{
Alinka Tóth ${ }^{1,2}$, Lívia Ivaskó ${ }^{2}$ Katalin Jakab ${ }^{1}$ and László Vécsei ${ }^{1,3 *}$ \\ ${ }^{1}$ Center for Neurorehabilitation, Department of Neurology, Faculty of Medicine, Albert Szent-Györgyi Clinical Center, University of Szeged, Hungary \\ ${ }^{2}$ Developmental and Neuropragmatic Research Group, University of Szeged, Hungary \\ ${ }^{3}$ MTA-SZTE Neuroscience Research Group of the Hungarian Academy of Sciences, Szeged, Hungary
}

\begin{abstract}
Constraint-induced aphasia therapy is a widely used method in the treatment after stroke. Focusing on the theoretical basis of the original conception of the constraint-induced procedure we first made a special adaptation for Hungarian aphasic patients. We have been applying this method since 2012. So far, we have accomplished the treatment of 7 groups including 22 patients. It was supposed that the intensive language therapy based on the certain language features such as phonologic, semantic, syntactic and pragmatic parameters can facilitate the abstraction of general linguistic rules. The data were measured by standard and special tests significant improvement occurred in both the expressive and receptive language by the help of patients' intact cognitive functions. Regarding our data we assumed that the new elaborated version for Hungarian language of the constraint-induced aphasia therapy can facilitate the abstraction and generalization of linguistic rules and could improve the patients' linguistic skills according to the original method.
\end{abstract}

Keywords: Aphasia rehabilitation; Constraint-induced language therapy; Hungarian language; Principles of neuroplasticity

\section{Introduction}

Aphasia is generally described as an impairment of language resulting from focal brain damage to the language-dominant cerebral hemisphere. "This serves to distinguish aphasia from the language and cognitive-communication problems associated with non-languagedominant hemisphere damage, dementia, and traumatic brain injury" [1]. Kertesz [2] clinically described aphasia as a 'neurologically central disturbance of language characterized by paraphasias, word finding difficulty, and variably impaired comprehension, associated with disturbance of reading and writing, at times with dysarthria, nonverbal constructional and problem-solving difficulty and impairment of gesture' [2]. This definition is the basis of the differential diagnostic procedures of aphasia in general [3], as well as in Hungary.

Following Bhogal, Teaseel and Speechley's [1] definite description of aphasia we should claim that "The Agency for Health Care Policy and Research Post-Stroke Rehabilitation Clinical Practice Guidelines" [4] define aphasia as 'the loss of ability to communicate orally, through signs, or in writing, or the inability to understand such communications; the loss of language usage ability.'

Aphasia is usually caused by stroke affecting the left hemisphere in a right-handed person. Most cases belong to the cortical aphasia syndromes, where the lesion is associated with the sensorimotor cortex of the frontal, parietal and temporal lobe. The subcortical aphasia syndromes include thalamic aphasia and capsular-putaminal aphasia, often caused by hemorrhage [5]. The incidence of aphasia after a left hemisphere stroke is 55\% [6]. Stroke is a leading cause of long-term disability, despite the good quality of acute stroke care. Stroke means high economic cost for the patient, their families and the society. Although the incidence and prevalence of stroke is continuously declining in the developed countries, approximately 40.000 new stroke cases/year still exist in Hungary. The global burden of stroke is enormous resulting from aphasia and other stroke-related disabilities. Aphasia treatment is one of the most important fields of the multidisciplinary stroke rehabilitation program.

Pulvermüller et al. $[7,8]$ developed a new method, the constraintinduced aphasia therapy (CIAT), they gave clinical evidence for the improvement of verbal skills with intensive, task-oriented, massively practiced stimuli. Focusing on the theoretical basis of the original conception of the constraint-induced procedure [7,8], we also claim that the features of abstraction and generalization of linguistic rules are able to improve patients verbal skills, even if they had chronic aphasia. On the basis of neuroplasticity and the variability of language processing this intensive therapy led to a more successful way in the reorganization of verbal behavior, as it was emphasized by Leon - Maher - Gonzalez Rothi [9].

Our aim with this paper is to show the effectiveness of a special adaptation of constraint-induced aphasia therapy $[7,8]$ for Hungarian aphasic patients at the Center for Neurorehabilitation of the Department of Neurology of the University of Szeged. Our collaborative work was the first clinical trial of the Hungarian adaptation of this method [10].

\section{Patients and Methods}

\section{Clinical parameters of participants}

All of our patients were suffering from aphasia following stroke. The neurological status of these patients has been performed by a neurologist as a first step of the diagnostic protocol. Aphasia tests were implemented by a speech and language therapist.

Twenty-two agrammatic aphasic patients have been treated with constraint-induced therapy. Eight of them had acute aphasia (less than 6 months post onset time) and fourteen of them had chronic aphasia (more than 6 months post onset time). There were 11 female and 11 male of the patients. The average age of patients was 61, 31 years (range: 22-77). Concerning the severity of aphasia patients were grouping on the basis of the Hungarian adaptation of Western Aphasia Battery [11,12]. Profound aphasia means 0-25 scores of aphasia quotient (AQ),

*Corresponding author: László Vécsei, Department of Neurology, Faculty of Medicine, Albert Szent-Györgyi Clinical Center, University of Szeged, Hungary, Semmelweis u. 6, H-6725 Szeged, Hungary, Tel: +36-62-545351; Fax: +36-62 545597; E-mail: vecsei.laszlo@med.u-szeged.hu

Received February 03, 2015; Accepted July 24, 2015; Published July 31, 2015

Citation: Tóth A, Ivaskó L, Jakab K, Vécsei L (2015) Constraint-Induced Linguistic Therapy for Aphasic Patients in Hungary. Int J Neurorehabilitation 2: 176. doi:10.4172/2376-0281.1000176

Copyright: (c) 2015 Tóth A, et al. This is an open-access article distributed under the terms of the Creative Commons Attribution License, which permits unrestricted use, distribution, and reproduction in any medium, provided the original author and source are credited. 
severe aphasia means 25-50 AQ, moderate aphasia means 50-75 AQ, mild aphasia means 75-94 AQ. One patient had profound, four of them had severe, five of them had moderate and twelve of them had mild aphasia according to the severity of post-stroke aphasia. Seventeen patients suffered from ischemic stroke. Sixteen of them had stroke in the left middle cerebral artery (they were right-handed) and one patient had damage in the right middle cerebral artery who was left-handed. Five patients had hemorrhage. Four of them had stroke in the left temporal lobe and one of them had a stroke in the right temporal lobe.

The diagnostic process started two days before the therapy and finished straight after the therapy. Now we have data from 7 groups including almost three aphasic patients. All of them were native Hungarian speakers. They were not suffering from dementia, depression and memory dysfunctions. These patients and their relatives were informed of the new methodology of therapeutic work. All of the patients were involved into therapeutic groups on their own accord. All of their clinical parameters related to the explanation of the special therapy they were involved in can be seen as follows (Table 1).

\section{Design}

The study was conducted in within-subject design with the preand post-test evaluation of the performance of the patients. This experimental design was used due to the Hungarian status of language rehabilitation at the clinical area: there is not any standard aphasia therapy for agrammatic patients in Hungary that is why we had no possibilities to find a relevant control group at the Center.

\section{Assessment}

There are several aspects to assess the complex verbal communication profile. To measure the major functions regarding the language system, we applied the widely used Hungarian adaptation of Western Aphasia Battery [11,12]. This test measures the content information of spontaneous speech fluency, comprehension, repetition, and naming in verbal behavior. The scores of this battery (aphasia quotients) can provide information concerning the severity and the subtype of aphasia.

The Boston Naming Test [13] is suitable to make a further distinction according to the word retrieval performance. We used the standard 60item version of the test. Patients were asked to name the item on each picture. When it was necessary for the patients they were given some help such as semantic cue or phonemic cue. Regarding the standard scoring a so-called $\mathrm{Z}$ score is calculated, which is a reference number. It represents the discrepancy between the performance of the patients and that of the healthy control group according to their age, gender and the level of education. We supposed the qualitative assessment can reveal further distinction, so we used some other categories during the evaluation method. We applied the original technique and we made some completion. These are the following: related meaning and paraphrase.

To measure the effectiveness of the therapeutical work with a special test, we created a set of cards of the method that we used in the course of therapy to check not only the naming skills but also the efficacy of our therapy method called CIAT Test. We put emphasis on semantically related meaning which is nearly the correct answer but not precisely the traget word (such as carpet insteed of curtain). We suppose that these answers can be relevant in the framework of this method while the widely used, syndrome-specific approach does not take into consideration this kind of answers. The Communicative Activity Log [7] was translated according to the original method and

\begin{tabular}{|c|c|c|c|c|c|c|c|c|c|c|c|c|c|}
\hline Monogram & Age & Sex & Education & $\begin{array}{l}\text { NIHSS } \\
\text { Scale }\end{array}$ & Origin & Conditions & $\begin{array}{l}\text { Aphasia } \\
\text { severity }\end{array}$ & $\begin{array}{l}\text { Aphasia } \\
\text { Syndrome }\end{array}$ & $\begin{array}{c}\text { WAB } \\
\text { AQ }\end{array}$ & $\begin{array}{c}\text { BNT } \\
Z \text { score }\end{array}$ & CIAT & $\begin{array}{c}\text { CAL } \\
\text { quantity }\end{array}$ & $\begin{array}{l}\text { CAL } \\
\text { quality }\end{array}$ \\
\hline B. Sz. & 70 & M & Intermediate & 9 & $\begin{array}{l}\text { Left temporal } \\
\text { hemorrhage }\end{array}$ & Chronic & Profound & Broca & 11,2 & $-6,122$ & 0 & 48 & 22 \\
\hline B. Sz. K. & 46 & $\mathrm{~F}$ & Intermediate & 2 & Left ACM infarct & Chronic & Mild & Anomic & 80,2 & $-3,372$ & 150 & 57 & 62 \\
\hline B. T. & 43 & M & Intermediate & 10 & Left ACM infarct & Chronic & Severe & Broca & 31,4 & $-10,098$ & 41 & 24 & 13 \\
\hline Cs. S. & 77 & $\mathrm{~F}$ & Intermediate & 4 & Left ACM infarct & Acute & Mild & Anomic & 92,9 & $-2,007$ & 135 & 57 & 62 \\
\hline E. J. & 61 & $M$ & Higher & 15 & Left ACM infarct & Acute & Severe & Broca & 39 & $-10,164$ & 58 & 47 & 22 \\
\hline F. T. & 44 & $M$ & Intermediate & 7 & Left ACM infarct & Chronic & Severe & Broca & 33,8 & $-10,098$ & 64 & 47 & 18 \\
\hline Gy. M. & 72 & $\mathrm{~F}$ & Intermediate & 2 & Left ACM infarct & Chronic & Severe & Broca & 38,2 & $-6,122$ & 86 & 21 & 18 \\
\hline H. J. & 65 & M & Higher & 4 & Left ACM infarct & Chronic & Mild & Anomic & 86,4 & $-2,398$ & 137 & 52 & 60 \\
\hline I. L. & 69 & $\mathrm{~F}$ & Higher & 7 & Right ACM infarct & Chronic & Moderate & Broca & 56,3 & $-7,702$ & 108 & 16 & 14 \\
\hline J. L. & 62 & M & Intermediate & 6 & Left ACM infarct & Acute & Moderate & Broca & 69,8 & $-5,846$ & 126 & 46 & 32 \\
\hline K. F. & 59 & $\mathrm{~F}$ & Intermediate & 3 & Left ACM infarct & Chronic & Mild & Anomic & 91,8 & $-0,511$ & 150 & 47 & 47 \\
\hline K. I. & 78 & $\mathrm{~F}$ & Intermediate & 3 & $\begin{array}{l}\text { Left temporal } \\
\text { hemorrhage }\end{array}$ & Acute & Mild & Anomic & 82,4 & $-2,381$ & 150 & - & - \\
\hline K. M. & 62 & $\mathrm{~F}$ & Intermediate & 4 & Left ACM infarct & Chronic & Mild & Conduction & 85,8 & $-0,137$ & 149 & 58 & 55 \\
\hline M. L. & 57 & $M$ & Intermediate & 5 & $\begin{array}{l}\text { Right temporal } \\
\text { hemorrhage }\end{array}$ & Chronic & Mild & Anomic & 83,4 & $-2,131$ & 137 & 55 & 26 \\
\hline N. J. & 64 & $\mathrm{~F}$ & Intermediate & 6 & Left ACM infarct & Chronic & Moderate & Anomic & 59,2 & $-3,379$ & 138 & 24 & 28 \\
\hline O. O. & 22 & $\mathrm{~F}$ & Higher & 4 & $\begin{array}{l}\text { Left temporal } \\
\text { hemorrhage }\end{array}$ & Acute & Mild & Conduction & 80,9 & $-13,107$ & 150 & 55 & 58 \\
\hline S. J. & 72 & $\mathrm{M}$ & Higher & 3 & Left ACM infarct & Acute & Moderate & Conduction & 59,8 & $-7,133$ & 92 & 40 & 35 \\
\hline Sz. A. & 58 & $\mathrm{~F}$ & Intermediate & 8 & Left ACM infarct & Acute & Moderate & Broca & 64 & $-3,879$ & 135 & 55 & 26 \\
\hline Sz. M. & 46 & $\mathrm{~F}$ & Intermediate & 3 & $\begin{array}{l}\text { Left temporal } \\
\text { hemorrhage }\end{array}$ & Chronic & Mild & Anomic & 90,4 & $-1,065$ & 153 & 65 & 62 \\
\hline T. I. & 72 & $M$ & Intermediate & 8 & Left ACM infarct & Chronic & Mild & Anomic & 83,2 & $-4,135$ & 131 & 30 & 40 \\
\hline T. J. & 77 & M & Intermediate & 4 & Left ACM infarct & Chronic & Moderate & Transcortical motor & 70,8 & $-4,002$ & 114 & 48 & 20 \\
\hline T. S. & 73 & M & Intermediate & 6 & Left ACM infarct & Acute & Mild & Anomic & 94,6 & 2,238 & 145 & 40 & 47 \\
\hline
\end{tabular}

Table 1: Parameters of patients in standard and therapy related tests (http://www.mdcalc.com/nih-stroke-scale-score-nihss/). 
we applied the same. This test was filled in by caregivers or relatives (before and after the therapy) to measure the changes in two aspects of communications skills concerning the qualitative and quantitative characteristics of speech. There were 18 questions in each session.

\section{Method and device}

It is important to express that there were no detailed descriptions avialable of the whole matrix of verbal stimuli of the therapy. Features of the elaborated new Hungarian version of the method are shown in the following section. Following the consideration of the theoretical principals of the constraint-induced aphasia therapy [7,8], we created the first Hungarian version in 2012. According to the original announcement [7], it is important in the course of the therapy that the patients can only use verbal expressions to obtain their targets. It is not allowed to use gestures, writing or any other nonverbal communicative stimuli. To prevent the use of these signals and to enforce this aspect there was a panel between participants.

Regarding the basis of the principles of "constraint-induced aphasia therapy" [7]: massed practice principle, behavioural relevance principle, focusing principle, our main goal was to elaborate the Hungarian version of the well-known international method.

We have been applying this method for the treatment of patients after stroke in our Center since 2012. The patients worked in groups during the therapy: three patients took part four hours per day (depending on their physical capacity) during ten consecutive days.

We can differentiate between the patients according to the scores of the Hungarian standard tests. We worked up a criteria for input mean scores to see precisely the individual disabilities. It was necessary for grouping the patients. By the help of input scores we are able to make futher distinction according to the patients performance: not only with the adjunct of the items (pictures on the card) but also with the difficulties of the expected target words.

Severly damaged patients were put into the so-called basic therapeutic group, while an intermediate group was created for patients with mild and modarate damage. There was a difference between the two set of cards of words and utterances depending on their frequecy in everyday language use. It was a main principle to apply at the basic level that the more frequent items could be easier to reach for patients' every day communication as soon as possible.

In the course of our Hungarian version of constraint-induced aphasia therapy, we use different numbers of cards: at the basic level we use 320 pair of cards and at the intermediate level there are 540 pair of cards. These cards represent the phonological, syntactical and semantic characteristics of the Hungarian language, including nouns, verbs, numbers, adjectives (some predicative adjectives), and sentences. Considering the language specific rules of Hungarian grammar, we have also made a special adaptation of the method. Each set of cards contains these features and linguistic items of both of the levels of high and low word frequency according to Hungarian language. The discrimination of the distinctive features of different linguistic items of verbal forms were performed to the cards generating implicit learning of generative rules of grammatical components. Regarding the semantic, syntactic and phonological features of Hungarian, it was obvious to create a complex matrix for drawing patients' attention to these regularities. A further important component was the distance between the phonetical and phonological features (such as kék /blue/ and pék /baker/) and the complexity of grammatical structure according to the number and color of the pictures (example form the intermediate level: négy kék kés /four blue knives/ or négy kék villa /four blue forks/), and the following of the syntactic rules of generating well-formed sentences. To receive the correct pair during the game patients are also expected to articulate precisely as it is expectable to be aware of phonological information. The complexity of morphological variables could differ depending on the patients' abilities. It is important to emphasize that this therapy is exceedingly suitable to improve the comprehension of patients. Those who had difficulties in understanding had to concentrate more precisely on the steps of the game to follow their partner's verbal forms to be able to choose the correct pair of cards. All the patients were asked to name the cards at the beginning of the therapy even if they had problems with understanding. If one made a request for something (e.g., a card with an apple, or a more complex symbol uttered by a whole sentence like 'Grandmother cooks ham.') his/her partner had to repeat the linguistic form starting with a performative verb like 'I will give you....' or 'Here is ...' Severely damaged patients verbal forms were accepted if they formed the target stimuli. Minimal pairs for developing aphasic patients' abstraction of semantic rules (e.g., categorization) were based on both salient and generally typically used elements.

Before the introduction of the therapy to clinical use we had showed our pictures to several healthy people from different social groups to verify the graphical illustration and to confirm the validity of certain items. The pictures of cards were made by a graphic artist.

\section{Methodological Implications}

Evidence-based traditional grammatic therapies use types of exercises to follow up some unuttered sentences or semi-formed sentences to finish to improve patients grammatic competence. Naming can be facilitated by the help of therapists with phonological or semantic cues. There are individual differences between the patients depending on their socioparameters and the knowledge of their native language before their stroke. One of the most beneficial charachters of playing with cards is enhancing individual improvement. Personal capacities of language behavior can be involved in real conversations between participants.

Some patients are motivated to create more complex verbal forms, but there are ones who can only express limited versions of words.

Therefore, we expect to make a distinction between the answers of the patients according to the main goal of our therapy. We elaborated a matrix for more subcathegories (expected naming, related meaning, semantic cue, phonemic cue, paraphrase, no answer) not only for the measurement of Boston Naming Test [14] through the whole qualitative diagnostical process to describe the various forms of language use. This linguistic aspect is suitable to achieve a further proper distinction between the patients and to clarify the individual language use. Expected target words or synonyms can be appreciated more than facilitated verbal stimuli. Belonging to the dependency of the verbal stimuli to other stimuli scores can differ. The more independent expected use of a form was rated with more testpoints. Invalid or unuttered answers are elements of zero-rated subcathegories like 'no answers'.

At the beginning of the therapy, the use of a phrase in frequent occurrence was conditioned. This type of answer is not expected through the therapy. Our main goal is to facilitate those forms in which patients could express themselves according to their intentions with more creative linguistic variables. To decrease non-productive automatic answers, there were several atypical non-frequent meanings of sentences drawn on the pictures.

There is a crucial role of executive functions for intentional 
communication as self-monitoring and planning, or activating, implementing and also controlling complex behaviors. As it is emphasized by Balconi [15], to fulfill communicative goals, it is essentially needed to be aware of irrelevant items of human behavior. The existence of the central control system, separated from the peripheral processes, determines attentional control over selection mechanisms.

There is a special need for supervisory attentional competences when we use a constraint-induced therapy. The patient has to be sure what kind of physical stimulus is allowed to make his/her intentions manifest. It is necessary to follow his/her partners' communicative behavior to be able to share intentions as cooperative members of the group. The importance of this kind of strategic planning and monitoring is taught on the first day of the therapy. All of the patients are contributors of a real verbal communicative act while they perform real questions, requests, acknowledgements, refuses and other speech acts. The realistic features of this kind of linguistic therapeutic games like the so-called "ask for the pair" card game of the constraintinduced aphasia therapy creates a strongly motivating context for verbal communication, even if the members of the therapeutic group have disorders of verbal forms of communication. As Leon - Maher - Gonzalez Rothi [10] argues, the principle of learned nonuse of verbal elements would decrease grammatical abilities, but the four principles of repetition, intensity, salience and specificity can result in greater strength and more complex synaptic reorganization referring to neuroplasticity. There are important differences between certain types of repetitions. It was emphasized in the original paper of CILT method [7] that verbal stimuli vary in the matrix of the therapy. There are elements which could be combined with other verbal elements, so the so-called linguistically well-formed structures could contain more than one linguistic elements syntactically combined with other verbal elements.

Features of linguistic similarity and prototypically can help the patient to memorize verbal forms, but this therapy is not for simple repetition. All elements of the therapeutical matrix are engaged into several combinations to make it possible for the patients to abstract the linguistic rules of structures. This kind of implicit (re)learning of linguistic rules is the guarantee of the long time use of the reactivated grammatical competence.

\section{Statistics}

There was used as within-subject design. All data were analyzed by ANOVA. We applied paired t-test to compare the scores of the sample group before and after the therapy, and repeated measures occurred to examine the changes in order to provide a more detailed language profile.

\section{Results}

The following diagrams show that the main components of the language assessment at the pre- and post-test of different batteries are sensitive to the linguistic improvement of subjects.

The assessment of aphasia quotient (AQ) was compared with paired t-test. A significant increase was seen after therapy. (M_aq1 $=68.3045$, SD_aq1 $=23.71075 ;$ M_aq2 $=75.8364$, SD_aq2 $=22.47224, t(21)=$ $-5.299, \mathrm{p}<0.001$ ) (Figure 1).

The assessment of WAB scores before and after therapy was conducted with a 5 (FUNCTION: information of spontaneous speech, fluency, comprehension, repetition, naming) x 2 (TIME OF
ASSESSMENT: before therapy, after therapy) Repeated Measures ANOVA. When the sphericity assumption was not met, degrees of freedom were corrected according to the Greenhouse-Geisser correction. The main effect of FUNCTION was significant, $F(2.68$, $56.24)=15.495, M S E=4.474, p<0.001$. The main effect of TIME OF ASSESSMENT was also significant, $F(1,21)=28.075, M S E=1.111, p<$ 0.001 , indicating that WAB scores on average differed before and after therapy. The interaction of FUNCTION x TIME OF ASSESSMENT did not reach significance, $F(2.25,47.255)=1.878, M S E=1.228, p=0.16$, and post hoc Bonferroni-corrected tests revealed that improvement was significant in the case of each function (Figure 2).

Comparison of data from Boston Naming Test Z-Scores has been performed by conjugate t-probe. A significant increase was seen after therapy. (M_bnt1 $=-4.706864$, SD_bnt1 $=3.8317814$; M_bnt2 = $-3.897727, \mathrm{SD}$ bnt2 $=3.8903948, t(21)=-3.641, \mathrm{p}=0.002)($ Figure 3$)$.

The assessment of BNT component scores before and after therapy was conducted using a 6 (FUNCTION: expected naming, semantic cue, phonemic cue, related meaning, paraphrase, no answer) x 2 (TIME

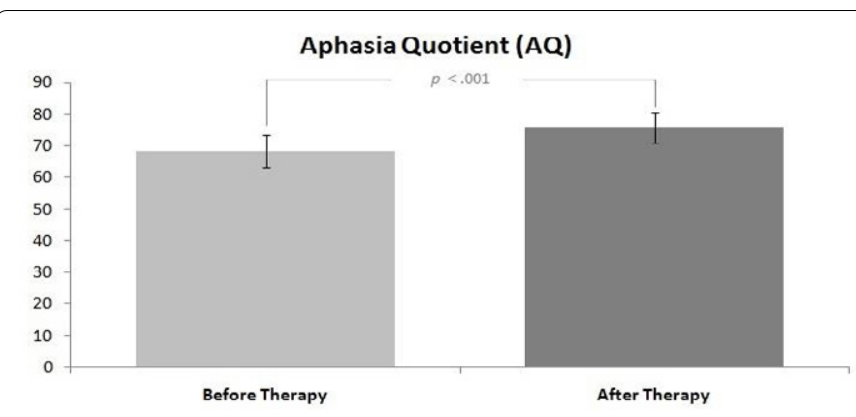

Figure 1: Pre- and post-tests of Aphasia Quotient in Western Aphasia Battery.

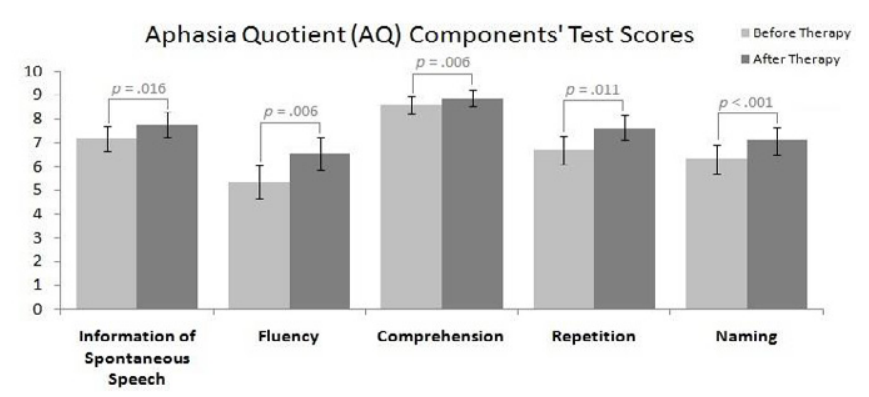

Figure 2: Overall language profile before and after the therapy in Western Aphasia Battery.

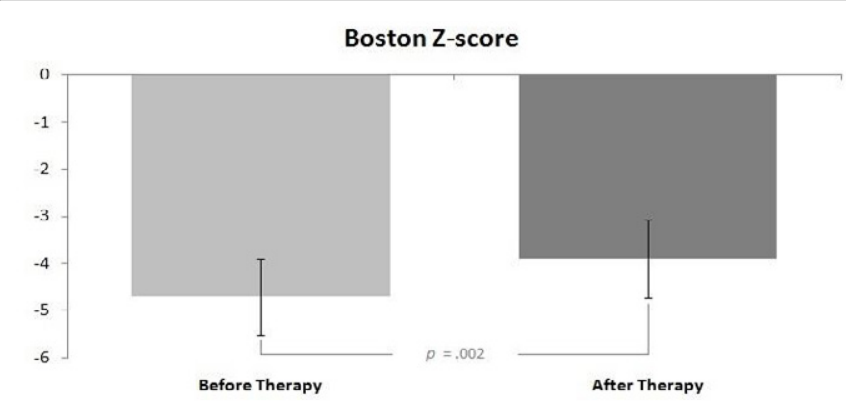

Figure 3: Pre- and post-tests of Boston naming test based on the standard measurement, the $Z$ scores. 


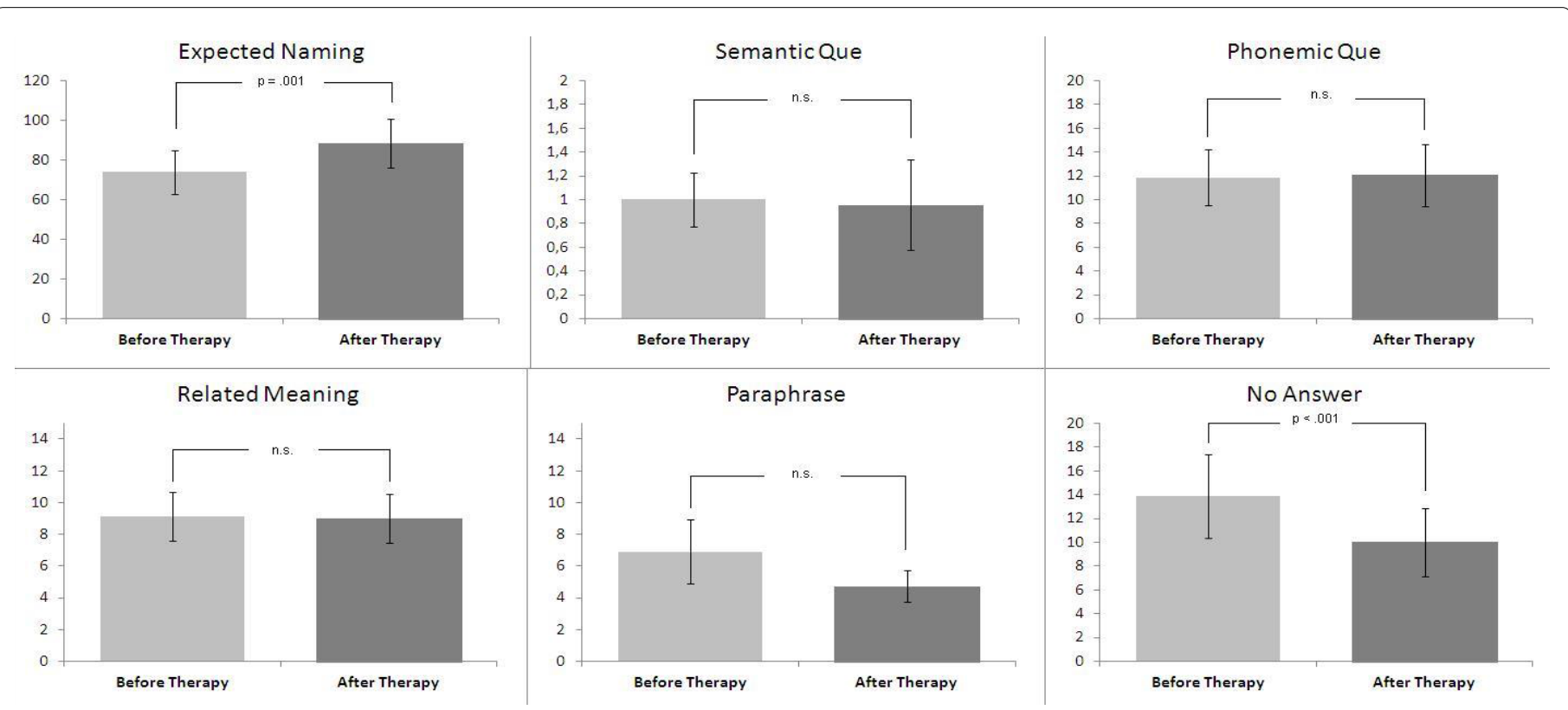

Figure 4: Overall language profile at Boston naming test before and after the therapy based on our evaluated scale.

OF ASSESSMENT: before therapy, after therapy) Repeated Measures ANOVA. When the sphericity assumption was not met, degrees of freedom were corrected according to the Greenhouse-Geisser correction.

The main effect of FUNCTION was significant, $F(1.149,24.120)=$ 32.771, $M S E=5327.973, p<0.001$, indicating different average scores for different functions. The main effect of TIME OF ASSESSMENT was also significant, $F(1,21)=11.731, M S E=11.292, p=0.003$, indicating that on average, scores differed before and after therapy. Most importantly there was a significant FUNCTION x TIME OF ASSESSMENT interaction, $F(1.805,37.907)=11.303, M S E=119.119$, $p<0.001$. Post hoc tests revealed that the only functions showing significant differences before and after therapy were target, expected naming $(p=0.001$, M_before $=73.909$, SD_before $=10.954$, M_after $=88.500$, SD_after $=12.151)$ and no answer $(p<0.001$, M_before $=$ 13.909, SD_before $=3.503, M \_$after $=10.000$, SD_after $\left.=2.883\right)$, all other $p>0.16$ (Figure 4 ).

Comparison of data from CIAT Test Scores has been performed by pair t-probe. A significant increase was seen after therapy. (M_ciat1 $=115.8636$, SD_ciat $1=41.99126 ;$ M_ciat $2=129.9545$, SD_ciat $2=$ $35.80832, t(21)=-4.458, \mathrm{p}<0.001)$ (Figure 5).

The assessment of CIAT component scores before and after therapy

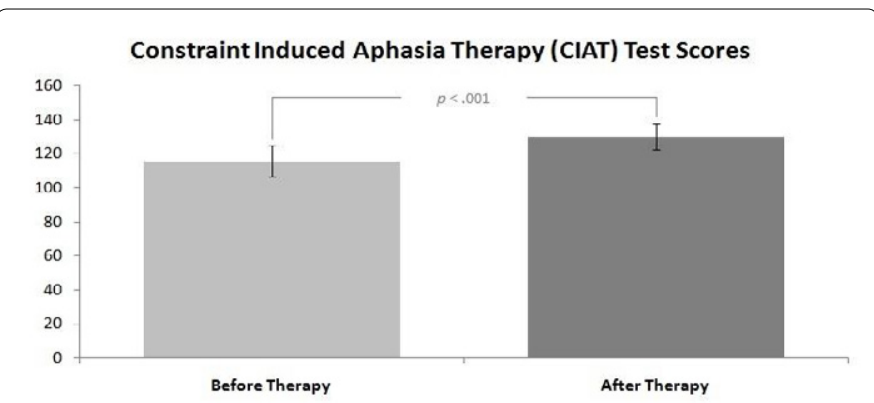

Figure 5: Pre- and post-test of constraint-induced Aphasia Therapy test scores. was conducted using a 6 (FUNCTION: expected naming, related meaning, phonemic cue, no answer) x 2 (TIME OF ASSESSMENT: before therapy, after therapy) Repeated Measures ANOVA. When the sphericity assumption was not met, degrees of freedom were corrected according to the Greenhouse-Geisser correction.

The main effect of FUNCTION was significant, $F(1.050$, $22.218)=81.352, M S E=3900.537, p<0.001$, indicating different average scores for different functions. The main effect of TIME OF ASSESSMENT was not significant, $F(1,21)=1.330, M S E=114.866$, $p=0.262$, indicating that on average, scores did not differ before and after therapy. Most importantly there was a significant FUNCTION x TIME OF ASSESSMENT interaction, $F(1.168,24.532)=5.249$, MSE $=284.676, p=0.026$. Post hoc tests revealed that the only functions showing (marginally) significant differences before and after therapy were expected naming $(p=0.05$, M_before $=100.000$, SD_before $=$ 9.956, M_after $=112.455$, SD_after $=10.897)$ and related meaning $(p<$ 0.001 , M_before $=8.682$, SD_before $=1.404$, M_after $=4.727$, SD_after $=0.972$ ), all other $\mathrm{p}>0.15$ (Figure 6).

Comparison of data of pre- and post-tests of Communicative Activity $\log (\mathrm{N}=21)$ has been evaluated by paired t-probe. There was a significant increase after therapy. (M_cal1 $=79.000$, SD_cal1 $=$ 27.46088; M_cal2 $=96.0714$, SD_cal2 $=30.99608, t(20)=-7.759, \mathrm{p}<$ 0.001) (Figure 7).

The assessment of CAL component scores before and after therapy was conducted using a 6 (FUNCTION: qualitative aspect, quantitative aspect of verbal forms) x 2 (TIME OF ASSESSMENT: before therapy, after therapy) Repeated Measures ANOVA. The main effect of FUNCTION was significant, $F(1,20)=9.422, M S E=190.700, p=$ 0.006 , indicating different average scores for different functions. The main effect of TIME OF ASSESSMENT was also significant, $F(1,20)$ $=60.203, M S E=25.414, p<0.001$, indicating that on average, scores differed before and after therapy. There was no interaction between the factors FUNCTION x TIME OF ASSESSMENT $F(1,20)=1.319$, $M S E=18.683, p=0.264$, indicating that changes were homogeneous (Figure 8). 


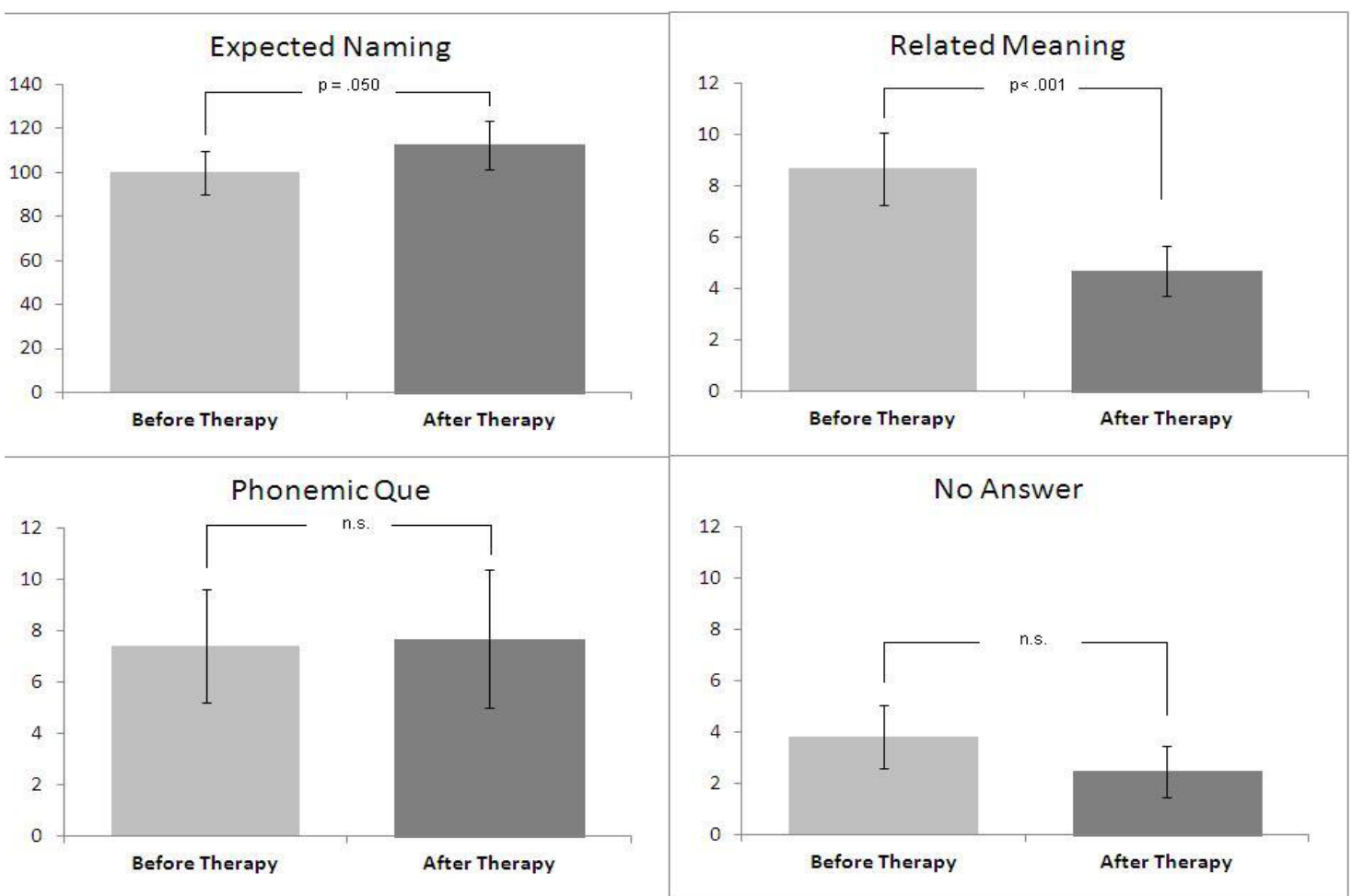

Figure 6: Overall language profile before and after the therapy at constraint-induced Aphasia Therapy test scores.

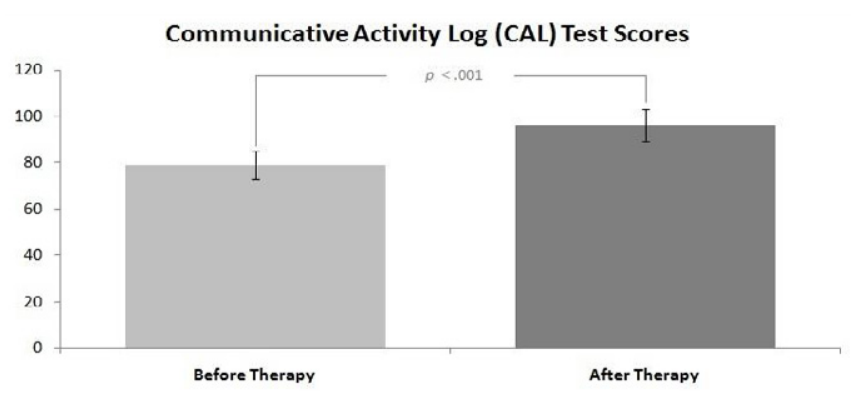

Figure 7: Pre- and post-test of communicative activity log.

Commucative Activity Log (CAL) Components' Test Scores

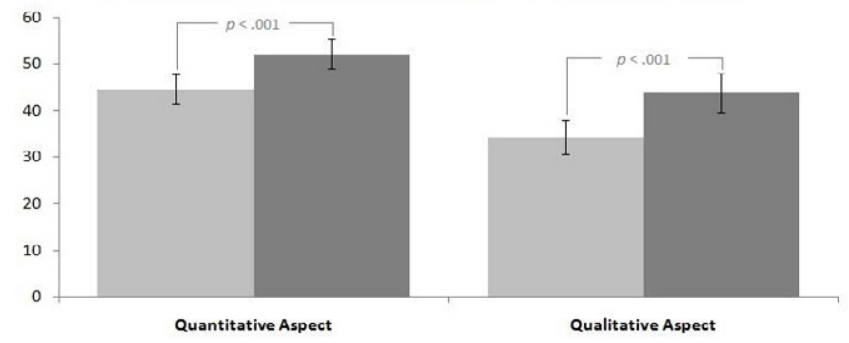

Figure 8: Pre- and post-test of qualitative and quantitative aspects of communicative activity log.

\section{Discussion}

It was the first time to collect data from patients with aphasia to evaluate the effectiveness of constraint-induced linguistic therapy in our county. Following Pulvermüller et al.s $[7,8]$ original principles of constraint-induced aphasia therapy, our aim was to apply these methodological aspects to the special Hungarian system of neurorehabiltiation. The primary goal of aphasia treatment is to improve the patient's impaired linguistic skills. The molecular mechanisms of constraint-induced rehabilitative training including the movement and aphasia therapy are based on the brain's plasticity. Nudo et al. [16] observed the activity-dependent neuroplasticity in the primary motor cortex of adult monkeys. Intensive, repetitive, task-oriented practice seems to enhance plasticity within cortical and subcortical levels.

As a relevance of the main findings of the study we should claim that until now the constraint-induced aphasia therapy has not been available in Hungary. In the Hungarian clinical practice the classical, syndrome specific treatment is widely used in aphasia rehabilitation. According to the symptoms which can reveal patients' linguistic profile: there are many tasks encompassing some basic ones as well as more advanced exercises in the phonologic, syntactic, semantic and pragmatic level of the language system. Normally these types of treatments take three or four weeks about one hour per day which means that one person requires 20 - 30 hours altogether. The need for an intensive therapy for Hungarian aphasic patients motivated us to find a more complex procedure which is financially adaptive to the medical system of neurorehabilitation in our country.

Our main findings have shown that the new elaborated versions of the constraint-induced aphasia therapy depending on the severity and the post onset time of aphasia can improve patients' linguistic skills. As a conclusion we should say that practicing language ability with intensive grammatic and pragmatic communicative stimuli has developed patients' grammatic competence. Their success was improved by other members of the group, as well as by their caregivers at the Department. After the statistical analysis of the data we should claim that patients had very high scores in picture stories because of their intact executive 
functions. The results of the tests of capacity for verbal communication from Boston Naming Test, and the WAB were analyzed in a very detailed way. Concentrating on the patients' intact cognitive functions, we differentiated between the semantic and phonological properties of verbal forms, so data were subcategorized depending on the types of false or missed answers. Comparing data from pre-therapeutical and the post-therapeutical times, we can conclude that most of the patients have been more sensitive to the grammatically relevant semantic, phonological features of verbal stimuli after the therapy [17]. Their pragmatic competence was intact, they understood jokes well, they interpreted conversational norms and were able to differentiate between the proper forms of politeness, but they were not able to use these forms as well. Playing with the cards of the therapy, they were asked to use some pragmatically relevant utterances for asking people something, or suggesting, requesting or refusing something. Based on the questionnaire CAL they became motivated to use these kinds of communicative verbal forms in their everyday language use after they left the Department. It is a further task how to reinforce and control the improvement and the motivation of the patients in the future.

We can claim that therapeutic language games could regain some of patients' lost linguistic functions in a very short time with a quite intensive guided practice [18-20] not to avoid the problematic forms of verbal stimuli but with the help of corporation and motivation. The indicators of this activity and intensity based therapy focus on both the production and the comprehension of speech in an appropriate communicative context. This experience makes them able to use this severally confirmed form of generating linguistic abstract rules to use their reinforced grammar productively in an adequate situation after the therapeutical work.

\section{Acknowledgement}

The authors of this paper are grateful for the help of Emese Hallgató professor assistant at the Institute of Psychology at the University of Szeged who analyzed our data by SPSS and ANOVA statistical programs. Her comments and suggestions have been beneficial assistance to our work. A very special thanks goes to the patients and their relatives.

\section{References}

1. Bhogal SK, Teasell R, Speechley M (2003) Intensity of aphasia therapy, impact on recovery. Stroke 34: 987-993.

2. Kertesz A (1979) Aphasia and associated disorders. In: Taxonomy, localization and recovery. Grune-Stratton, New York.

3. Mumenthaler M (1990) Neurology. Thieme Medical Publishers, New York.

4. Gresham GE, Duncan PW, Stason WB, Adams HP Jr., Adelman AM, et al. (1995) Post-Stroke Rehabilitation. Clinical Practice Guideline, 16. U.S Department of Health and Human Services. Public Health Service, Agency for Health Care Policy and Research, Rockville, AHCPR Publication No. 95-0662.

5. Wallesch CW, Papagno C (1988) Subcortical aphasia. In: Aphasia, Rose FC, Whurr R, Wyke MA (edr,) Cole and Whurr, London.
6. Scarpa M, Colombo P, Sorgato P, DeRenzi E (1987) The incidence of aphasia and global aphasia in left brain-damaged patients. Cortex 23: 331-336.

7. Pulvermüller F, Neininger B, Elbert T, Mohr B, Rockstroh B, et al. (2001) Constraint induced therapy of chronic aphasia after stroke. Stroke 32: 16211626.

8. Pulvermüller F, Berthier M L (2008) Aphasia therapy on a neuroscience basis. Aphasiology 22: 563-599.

9. Leon SA, Maher LM, Gonzalez Rothi LJ (2011) Language Therapy. In Neuroplasticity and Rehabilitation, Raskin SA (Ed.). The Guilford Press, New York, London.

10. Ivaskó L, Tóth A, Jakab K, Vécsei L (2013) First data from constraint-induced aphasia therapy for Hungarian patients. Stem Spraak- en Taalpathologie 18: 76-78.

11. Kertesz A (1982) Western Aphasia Battery test manual. Grune and Stratton. Virginia.

12. Sági J (1991) Az afázia klasszifikációja és diagnosztikája I-II. Ideggyógyászat Szemle 44: 339-362

13. Goodglass H, Kaplan E, Barresi B, Weintraub S (2001) Boston diagnostic aphasia examination ( $3^{\text {rd }}$ ed). Pearson, New York.

14. Budd M (2007) Boston Naming Test with latencies. Ph.D. Dissertation University of North Texas.

15. Balconi M (2010) Intentions and Communication: Cognitive Strategies, Metacognition and Social Cognition. In: Neuropsychology of Communication Balconi M (edr) Milan Springer.

16. Nudo R, Milliken G, Jenkins WM, Merzenich, MM (1996) Use-dependent alterations of movement representations in primary motor cortex of adult squirrel monkeys. Journal of Neuroscience 16: 785-807.

17. Tabor Connor L (2012) Language. In: Stroke Rehabilitation. Insights from Neuroscience and Imaging. Carey LM (edr) Oxford University Press, New York.

18. Maher LM, Kendall D, Swearengin JA, Rodrigez A, Leon SA, et al. (2006) A pilot study of use-dependent learning in the context of constraint-induced language therapy. Journal of the International Neuropsychological Society 12: 843-852.

19. Meinzer M, Elbert T, Djundja D, Taub E, Rockstroh B (2007) Extending the constraint-induced movement therapy (CIMT) approach to cognitive functions: Constraint-induced aphasia therapy (CIAT) of chronic aphasia. NeuroRehabilitation 22: 311-318.

20. Meinzer M, Rodriguez A, Gonzalez Rothi LJ (2012) The first decade of research on constrained-induced treatment approaches for aphasia rehabilitation. Archives of Physical Medicine and Rehabilitation 93: 35-45. 